\title{
10 Additive-Free Superfilling in Damascene Cu Electrodeposition Using Microcontact Printing
}

\author{
Soo-Kil Kim* and Jae Jeong Kim**,z \\ Research Center for Energy Conversion and Storage, School of Chemical Engineering, Seoul National \\ University, San 56-1, Shillim-dong, Kwanak-gu, Seoul 151-742, Korea
}

To avoid complications brought about by employing organic additives, microcontact printing using a flat stamp was used in forming trench-selective $\mathrm{Cu}$ superfilling on damascene structure. Self-assembled monolayers of 1-decanethiol transferred on top surface of the trench could withstand the $\mathrm{H}_{2} \mathrm{SO}_{4}$ electrolyte and were used as a barrier for current transfer below a certain potential that was not yet dominated by the tunneling current. Subsequent electrodeposition on the printing area was successfully inhibited. The resulting filling profile was a defect-free superfilling with bumps on top. This is comparable to the three-additive system consisting of accelerator and two-component suppressor.

(C) 2004 The Electrochemical Society. [DOI: 10.1149/1.1778932] All rights reserved.

Manuscript submitted October 27, 2003; revised manuscript received February 6, 2004. Available electronically August 4, 2004

For the past several years, fabrication of fast and reliable metal interconnections for high-performance devices has been associated with the defect-free $\mathrm{Cu}$ electrodeposition in damascene structure using organic additives. Numerous researches on the function of additives have suggested how some models are represented by diffusion/adsorption, ${ }^{1,2}$ competitive adsorption, ${ }^{3-7}$ and chemical reaction between thiol/disulfide and copper ions. ${ }^{8}$ Nevertheless, the reaction mechanism is intricate and still not understood. Organics in the electrolyte can also affect the properties of deposited $\mathrm{Cu}$ film, such as resistivity, crystallographic orientation, grain growth, etc. ${ }^{8,9}$ Here, microcontact printing $(\mu \mathrm{CP})$ is applied to superfilling in place of additives. $\mu \mathrm{CP}$ is a fast and low-cost pattern transfer technique that uses $\mathrm{nm}$ thick self-assembled monolayers (SAMs) of alkanethiol, ${ }^{10-13}$ silane, ${ }^{14}$ alkylphosphoric acids, ${ }^{15}$ and so forth. SAMs transferred on a flat metal surface by $\mu \mathrm{CP}$ with a molded Poly(dimethylsiloxane) (PDMS) stamp serve as a barrier/mask for selective wet etching. ${ }^{10,11,14} \mu \mathrm{CP}$ is also applied to selective deposition ${ }^{11,16}$ using chemical vapor deposition and catalytic particle transfer. Nonetheless, the metal patterning by SAM formation and the subsequent wet etching method can hardly be applied to the deep submicrometer interconnection technology due to the isotropic etching feature and poor resolution of wet etching. Selective deposition requiring a metal layer for SAM formation on the entire surface is also unsuitable for device interconnection where metal lines should be electrically isolated from each other. In this study, $\mu \mathrm{CP}$ was applied to trench-selective electrodeposition using preliminary patterned damascene structures and flat PDMS stamp. SAMs were used as a barrier for current transfer on top surface of the trench and corresponding filling profiles were also investigated.

\section{Experimental}

Figure 1 illustrates the schematic procedure of $\mu \mathrm{CP}$ and the subsequent selective damascene $\mathrm{Cu}$ electrodeposition. PDMS was mixed with $10 \%$ (volume) curing agent and then poured on a nonpatterned Si wafer which had an AFM-measured surface roughness of $0.2 \mathrm{~nm}$. After curing it at $65^{\circ} \mathrm{C}$ for $1 \mathrm{~h}$, the PDMS stamp was peeled off from the Si substrate. A $5 \mathrm{mM}$ 1-decanethiol ink solution was made by dissolving 1-decanethiol in ethanol. The ink solution was applied to the flat PDMS stamp. The stamp was then dried in a gentle stream of $\mathrm{N}_{2}{ }^{11}$ and readied for contact. The substrate where the ink solution would be transferred was a trench type patterned (single damascene, line width of $500 \mathrm{~nm}$, aspect ratio of 2.5) $\mathrm{Si}$ wafer with a structure of PVD Cu (70 nm, seed layer)/CVD TiN (10 $\mathrm{nm}$, diffusion barrier)/PVD Ti $(15 \mathrm{~nm}$, glue layer)/Si. $\mu$ CP was performed on the $\mathrm{Cu}$ seed layer by applying a constant pressure of

\footnotetext{
* Electrochemical Society Student Member.

** Electrochemical Society Active Member

z E-mail: jjkimm@snu.ac.kr
}

$10.35 \mathrm{~N} / \mathrm{cm}^{2}$ on the PDMS stamp for $5 \mathrm{~s}$. To investigate the effects of the contact time on the deposit shape evolution, $30 \mathrm{~s}$ of contact time was also applied to the gap filling. From the XRD analysis shown in the Fig. 2, the PVD-deposited $\mathrm{Cu}$ seed layer was found to have a strong (111) orientation. The bonding of alkanethiol on (111) surface of the $\mathrm{Cu}$ involved the sulfur p-orbitals and the orbitals of the first methyl group, ${ }^{17}$ and is known to be independent of the chain length. ${ }^{17}$ Subsequent $\mathrm{Cu}$ electrodeposition was performed on the SAMs-transferred $\mathrm{Cu}$ seed layer in the additive-free base electrolyte composed of $1 \mathrm{M} \mathrm{H}_{2} \mathrm{SO}_{4}, 0.25 \mathrm{M} \mathrm{CuSO}_{4} \cdot 5 \mathrm{H}_{2} \mathrm{O}$, and DI water with stirring. The three-electrode system made up of $\mathrm{Cu}$ wafer cathode, $\mathrm{Cu}$ bar anode, and saturated calomel reference electrode (SCE) was used. For comparison, $\mathrm{Cu}$ electrodeposition on the SAMsfree $\mathrm{Cu}$ seed layer was also done using the three-additive system for superfilling. The corresponding electrolyte was made up of the base electrolyte and $50 \mu \mathrm{M}$ bis(3-sulfopropyl)disulfide (SPS, $\left.\left(\mathrm{Na}^{+} \mathrm{O}_{3}^{-} \mathrm{S}\left(\mathrm{CH}_{2}\right)_{3} \mathrm{~S}-\right)_{2}\right), 88 \mu \mathrm{M}$ poly(ethylene glycol) (PEG, Mw 3400 ), and $1 \mathrm{mM} \mathrm{NaCl}{ }^{3,18}$

\section{Results and Discussion}

To determine the potential to be applied for electrodeposition, linear sweep voltammetry was performed within the range of 0 to $-550 \mathrm{mV}$ with a scan rate of $20 \mathrm{mV} / \mathrm{s}$. The result is presented in Fig. 3. A Cu rotating disc electrode with a rotation speed of $300 \mathrm{rpm}$ was used as a working electrode. The I-V curve shifted to a more negative direction for the microcontact printed $\mathrm{Cu}$ seed due to the blockage of the current transfer by the SAMs on the $\mathrm{Cu}$ surface. At below $-140 \mathrm{mV}$, the current through the microcontact printed $\mathrm{Cu}$ seed was almost 0 , while it increased steadily in the case of bare $\mathrm{Cu}$. Figures $4 \mathrm{a}$ and $\mathrm{b}$ exhibit the difference in deposition thickness according to the existence of SAMs on the $\mathrm{Cu}$ seed layer. Electrodeposition was performed at $-140 \mathrm{mV}$ for $200 \mathrm{~s}$. Unlike the $700 \mathrm{~nm}$ thick deposits on the bare $\mathrm{Cu}$ seed layer (Fig. 4a), almost no deposition occurred on the microcontact-printed $\mathrm{Cu}$ seed layer (Fig. 4b). Surface-restricted carbon and sulfur contents of specimen (b) from the AES analysis (Fig. 4c) supported this observation. It also indicated that SAMs of 1-decanethiol could stand against sulfuric acid electrolyte and successfully played a role as a barrier against electron transfer.

Figure 5 shows the comparison between $\mu \mathrm{CP}$ and organic additives for superfilling on damascene structure. A typical bottom-up filling profile was observed for the gap filling using the threeadditive system (Fig. 5a), of which the mechanism could be explained by curvature enhanced accelerator coverage (CEAC) ${ }^{4,7} \mathrm{~A}$ somewhat different profile was found in the gap filling using $\mu \mathrm{CP}$ (Fig. 5b), however. The top of the trench (protrusions) covered with the transferred SAMs had no deposits. Hillocklike deposits on the fourth and fifth protrusions implied that there were partially noncontact areas on the $\mathrm{Cu}$ seed layer due to the elasticity of the PDMS stamp. Lateral spreading and diffusion of alkanethiol from the stamp 


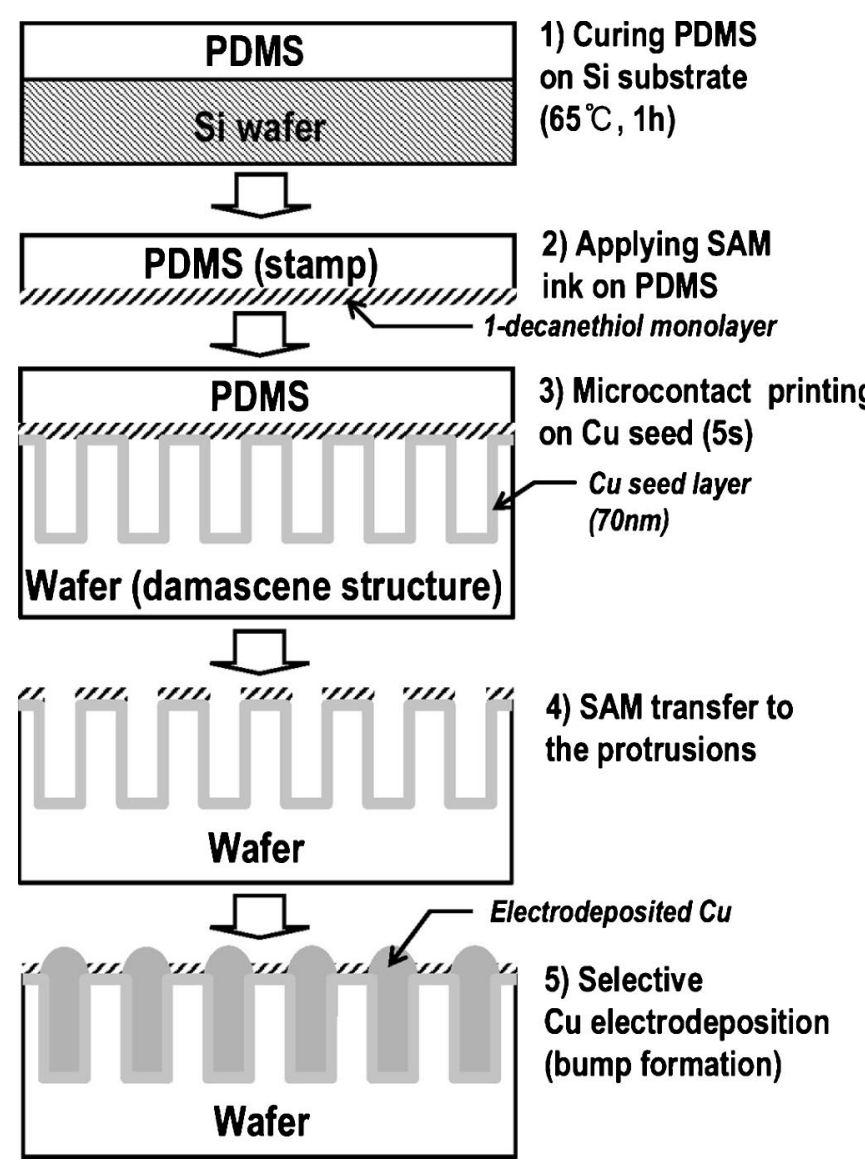

Figure 1. Schematic procedure of $\mu \mathrm{CP}$ and subsequent selective damascene $\mathrm{Cu}$ electrodeposition.

to the unwanted surface during printing are known to be possible. ${ }^{19}$ Similarly, SAMs on the top of trenches may diffuse into the inside of the trench; thus, the sidewall near the top had no deposits, and the filling had a round profile as shown in Fig. 5b. The small figure in Fig. 5b was a SEM image of the $\mathrm{Cu}$ deposit when contact time was increased up to $30 \mathrm{~s}$. As expected, there was almost no deposit along the sidewall near the top of the trench due to the extended diffusion

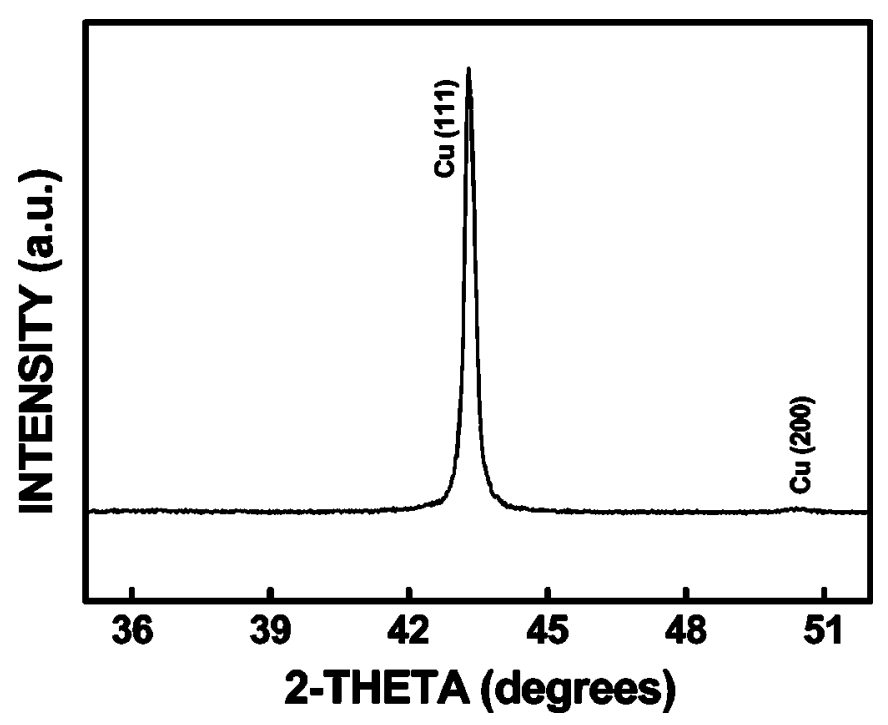

Figure 2. XRD analysis of PVD Cu seed layer.

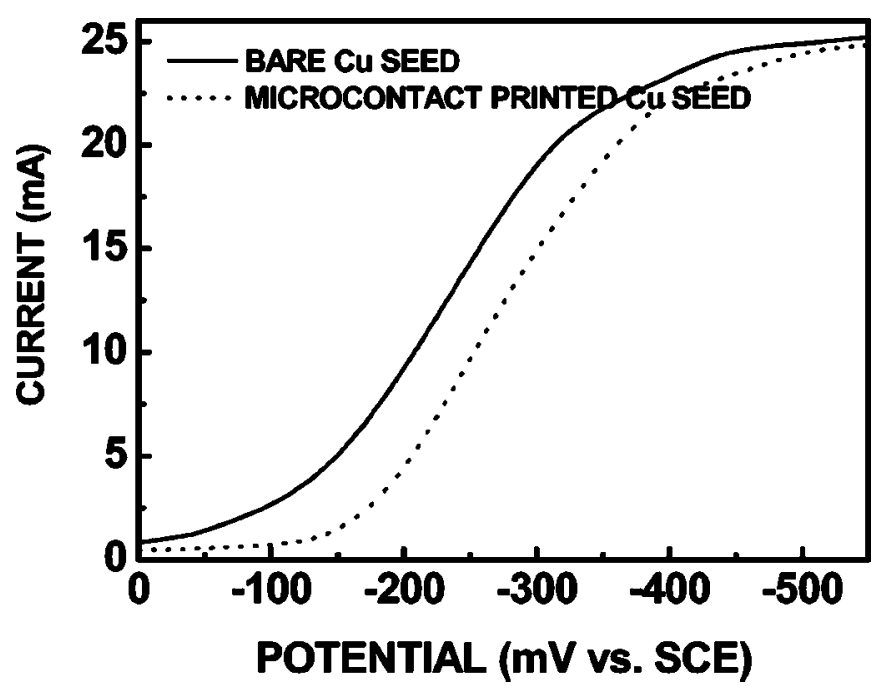

Figure 3. Linear sweep voltammogram of $\mathrm{Cu}$ electrodeposition on bare and $5 \mathrm{~s}$ microcontact printed $\mathrm{Cu}$ surface. Rotation speed of $0.2 \mathrm{~cm}^{2} \mathrm{Cu}$ electrode and scan rate were $300 \mathrm{rpm}$ and $20 \mathrm{mV} / \mathrm{s}$, respectively.

of SAMs during the increased contact time. After the deposition was complete, the formation of bump was observed in either case (Fig. $5 \mathrm{c}$ and $\mathrm{d}$ ), which was conclusive evidence of superfilling. Nonetheless, the bump formation mechanism seemed to be different for each case. The growth inhibition on top of the trench made the deposit grow continuously from the trench bottom to the surface normal
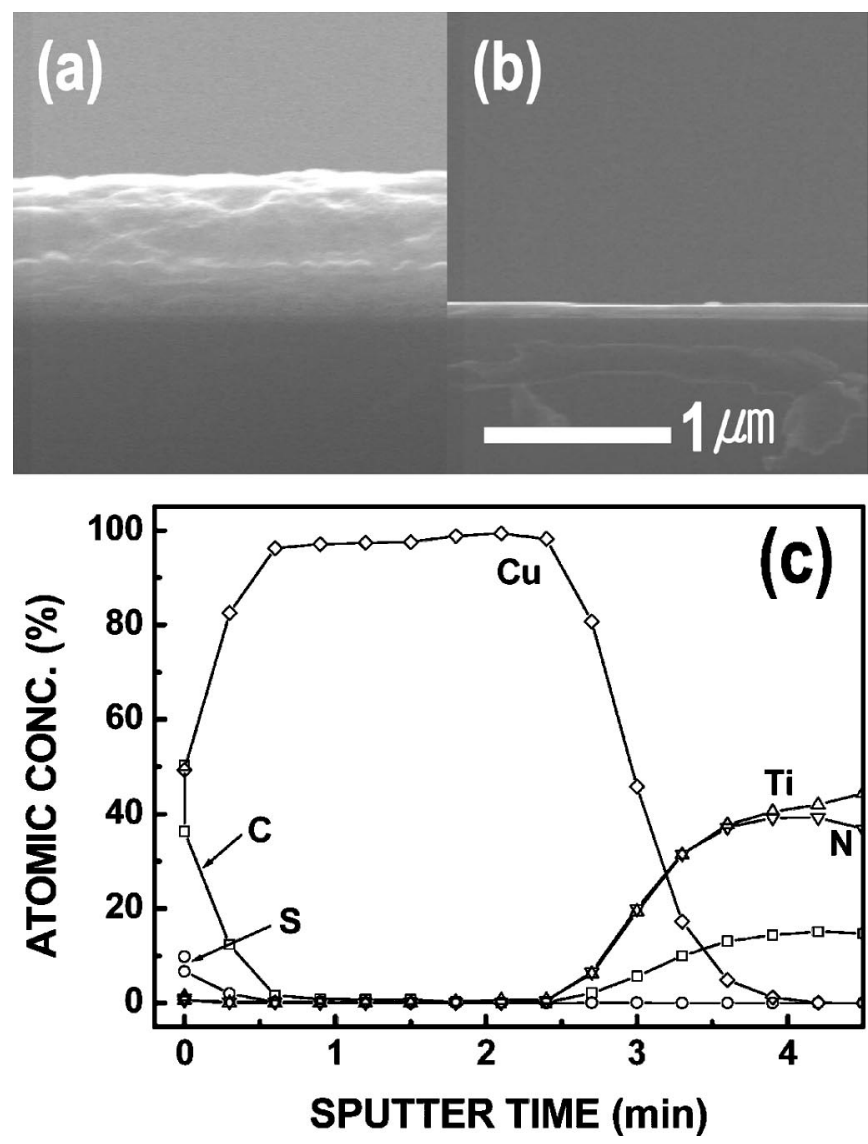

Figure 4. Cross-sectional FESEM images of electrodeposited $\mathrm{Cu}$ films at $-140 \mathrm{mV}$ for $200 \mathrm{~s}$ (a) on bare $\mathrm{Cu}$ seed, (b) on $5 \mathrm{~s}$ microcontact printed $\mathrm{Cu}$ seed, and (c) AES analysis of sample (b). 

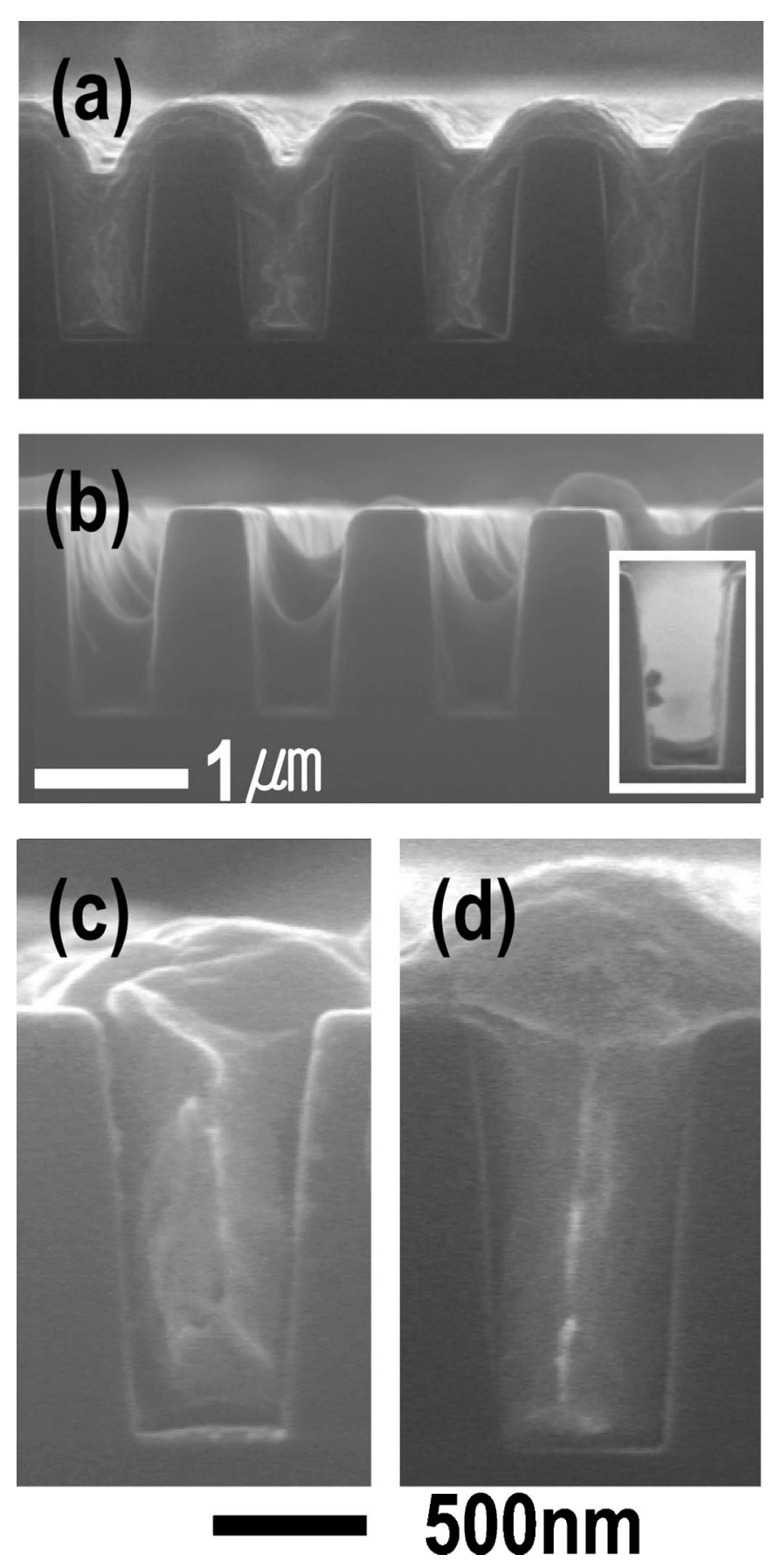

Figure 5. Cross-sectional FESEM images of electrodeposited $\mathrm{Cu}$ films (a) at $-250 \mathrm{mV}$ for $250 \mathrm{~s}$ using three-additive system, (b) at $-140 \mathrm{mV}$ for $100 \mathrm{~s}$ using $5 \mathrm{~s} \mu \mathrm{CP}$, (c) at $-140 \mathrm{mV}$ for $150 \mathrm{~s}$ using $5 \mathrm{~s} \mu \mathrm{CP}$, and (d) at $-250 \mathrm{mV}$ for $300 \mathrm{~s}$ using three-additive system, respectively. Inset: in (b) presents the $\mathrm{Cu}$ electrodeposit at $-140 \mathrm{mV}$ for $150 \mathrm{~s}$ using $\mu \mathrm{CP}$ with increased contact time of $30 \mathrm{~s}$. Additives used for (a) and (d) are $50 \mu \mathrm{M}$ SPS, $88 \mu \mathrm{M}$ PEG, and $1 \mathrm{mM} \mathrm{NaCl}$. direction in the case of filling via $\mu \mathrm{CP}$ as shown in Fig. 5c. On the other hand, the bump was formed as a result of bottom-up acceleration by accumulated organic accelerators inside of the trench ${ }^{3-6}$ in the case of the additive-based superfilling shown in Fig. 5d. These results demonstrated that $\mu \mathrm{CP}$ could be a successful and simple method for damascene $\mathrm{Cu}$ filling, comparing favorably with the organic additive system without the complex reaction, impurity, and maintenance problems of organic additives.

\section{Conclusions}

This study demonstrated that $\mu \mathrm{CP}$ could be applied to trenchselective $\mathrm{Cu}$ superfilling. Below a certain potential, SAMs of 1-decanethiol on the $\mathrm{Cu}$ surface can successfully suppress current flow through the interface of $\mathrm{Cu} / \mathrm{H}_{2} \mathrm{SO}_{4}$ electrolyte and inhibit deposition. When applied to a damascene structure, deposits can be void/ seam-free through $\mu \mathrm{CP}$ and bumps can occur after deposition is completed, a match for the three-additive system. Surface diffusion of 1-decanethiol molecules, which is an important factor in the shape of the deposits, is strongly dependent on contact time.

\section{Acknowledgments}

This work was supported by the KOSEF through the Research Center for Energy Conversion and Storage and by the Institute of Chemical Processes.

Seoul National University assisted in meeting the publication costs of this article.

\section{References}

1. P. C. Andricacos, C. Uzoh, J. Dukovic, J. Horkans, and H. Deligianni, IBM J. Res. Dev., 42, 567 (1998).

2. A. C. West, J. Electrochem. Soc., 147, 227 (2000).

3. T. P. Moffat, J. E. Bonevich, W. H. Huber, A. Stanishevsky, D. R. Kelly, G. R. Stafford, and D. Josell, J. Electrochem. Soc., 147, 4524 (2000).

4. D. Josell, D. Wheeler, W. H. Huber, and T. P. Moffat, Phys. Rev. Lett., 87, 016102 (2001).

5. Y. Cao, P. Taephaisitphongse, R. Chalupa, and A. C. West, J. Electrochem. Soc., 148, C466 (2001).

6. A. C. West, S. Mayer, and J. Reid, Electrochem. Solid-State Lett., 4, C50 (2001).

7. T. P. Moffat, D. Wheeler, W. H. Huber, and D. Josell, Electrochem. Solid-State Lett., 4, C26 (2001)

8. J. J. Kim, S.-K. Kim, and Y. S. Kim, J. Electroanal. Chem., 542, 61 (2003)

9. S. P. Hau-Riege and C. V. Thompson, Appl. Phys. Lett., 76, 309 (2000).

10. Y. Xia, E. Kim, M. Mrksich, and G. M. Whitesides, Chem. Mater., 8, 601 (1996).

11. Y. Xia, X.-M. Zhao, and G. M. Whitesides, Microelectron. Eng., 32, 255 (1996).

12. H. Li and W. T. S. Huck, Curr. Opin. Solid State Mater. Sci., 6, 3 (2002).

13. Y. Xia, D. Qin, and Y. Yin, Curr. Opin. Colloid Interface Sci., 6, 54 (2001).

14. D. Wang, S. G. Thomas, K. L. Wang, Y. Xia, and G. M. Whitesides, Appl. Phys. Lett., 70, 1593 (1997).

15. L. B. Goetting, T. Deng, and G. M. Whitesides, Langmuir, 15, 1182 (1999).

16. W. K. Ng, L. Wu, and P. M. Moran, Appl. Phys. Lett., 81, 3097 (2002).

17. A. Ferral, P. Paredes-Olivera, V. A. Macagno, and E. M. Patrito, Surf. Sci., 525, 85 (2003).

18. D. Josell, B. Baker, C. Witt, D. Wheeler, and T. P. Moffat, J. Electrochem. Soc., 149, C637 (2002)

19. E. Delamarche, H. Schmid, A. Bietsch, N. B. Larsen, H. Rothuizen, B. Michel, and H. Biebuyck, J. Phys. Chem. B, 102, 3324 (1998). 